\title{
Deep cryogenic treatment in AISI D2 tool steel punches to enhance tool life
}

\author{
Fabiano Dornelles Ramos $1,2 *$ (1) \\ Josué de Oliveira Bairros ${ }^{3}$ \\ Mauro Francisco Castro Moscoso ${ }^{1,4}$
}

\begin{abstract}
New materials and heat treatment are being developed worldwide to improve tool life. Tool steels are expensive due to the alloying elements and fabrication costs. Therefore, the maximization of tool life keeping good surface finishing is especially important to keep the processes attractiveness. The application of cryogenic treatment is promising to enhance mechanical and metallurgical properties of cold work tool steel parts. The possibility of increasing the finer secondary carbides content and decreasing amount of retained austenite during deep cryogenic treatment (DCT) is also an important matter for industry. The aim of this work is to improve tool life by applying DCT in AISI D2 cutting punches and compare these results with punches treated by conventional heat treatment (CHT), vacuum furnace quenching plus triple tempering. The tests used for analyses were: metallography, X-ray diffraction, carbides fraction, hardness and number of parts produced by each punch (practical test). The results indicate that the DCT punches have an enhancement of approximately $50 \%$ in its useful life.
\end{abstract}

Keywords: Deep Cryogenic; Treatment; Tool life; Tool steel.

\section{Introduction}

The need to increase productivity without raising production costs leads some sectors of the industry to look for ways to address these needs. Because of this, studies aimed at the development of new technologies are being developed. Also, the manipulation of existing processing methods to increase tool life and thereby increase productivity and reduce costs are being implemented [1-5].

AISI D2 tool steel has high wear and abrasion resistance. High alloying content may provide excellent hardenability and good dimensional stability [6] since the parts are suitable to air quenching. This grade of steel is widely used for cold working, especially for cutting tools and dies production $[7,8]$. Since this tool steel has greater alloying elements content, some amount of retained austenite can be formed [9], depending on the heat treatment performed [10]. The microstructure of hight hardness martensite matrix, with large primary carbides and very small secondary carbides promotes high wear resistance. Therefore, a cryogenic treatment is recommended by the steel producers to reduce the amount of retained austenite in high carbon steels [11-13].

Conventional quenching and tempering have been used to improve the mechanical properties of metals;

however, cryogenics is a relatively recent process that is capable of not only raising certain properties but maximizing them $[8,14-16]$. This cryogenic process aims to improve the mechanical properties of quenched and tempered steels, thus improving wear, mechanical resistance, and hardness through modifying the distribution of carbides and phases formed after treatment $[5,17]$.

This work aims to apply DCT to AISI D2 cutting punches and evaluate tool life in comparison to conventional cutting punches with CHT. Quenching was performed in a vacuum furnace with nitrogen blow and the cryogenic treament was carried out by immersion in a liquid nitrogen tank. Furthermore, the samples were evaluated by chemical analysis, hardness, metallography (qualitative and quantitative), $\mathrm{X}$-ray diffraction and practical test.

\section{Matherials and methods}

The experimental procedure followed the steps presented in Figure 1.

${ }^{I}$ Instituto Federal de Educação, Ciência e Tecnologia do Rio Grande do Sul, Caxias do Sul, RS, Brasil.

${ }^{2}$ Programa de Pós-graduação em Engenharia de Minas, Metalúrgica e Materiais - PPG3M, Universidade Federal do Rio Grande do Sul - UFRGS,

Porto Alegre, RS, Brasil.

${ }^{3}$ Fras-le S.A, Caxias do Sul, RS, Brasil.

${ }^{4}$ Termo Aço Tratamentos Térmicos LTDA, Caxias do Sul, Brasil.

${ }^{5}$ Programa de Pós-graduação em Tecnologia e Engenharia de Materiais - PPG-TEM, Instituto Federal de Educação, Ciência e Tecnologia do Rio Grande do Sul, Caxias do Sul, Brasil.

*Corresponding author: fabiano@caxias.ifrs.edu.br;fdrpunk@gmail.com

2176-1523 (C) 2021. Ramos et al. Published by ABM. This is an Open Access article distributed under the terms of the Creative Commons Attribution License, which permits unrestricted use, distribution, and reproduction in any medium, provided the original work is properly cited. 


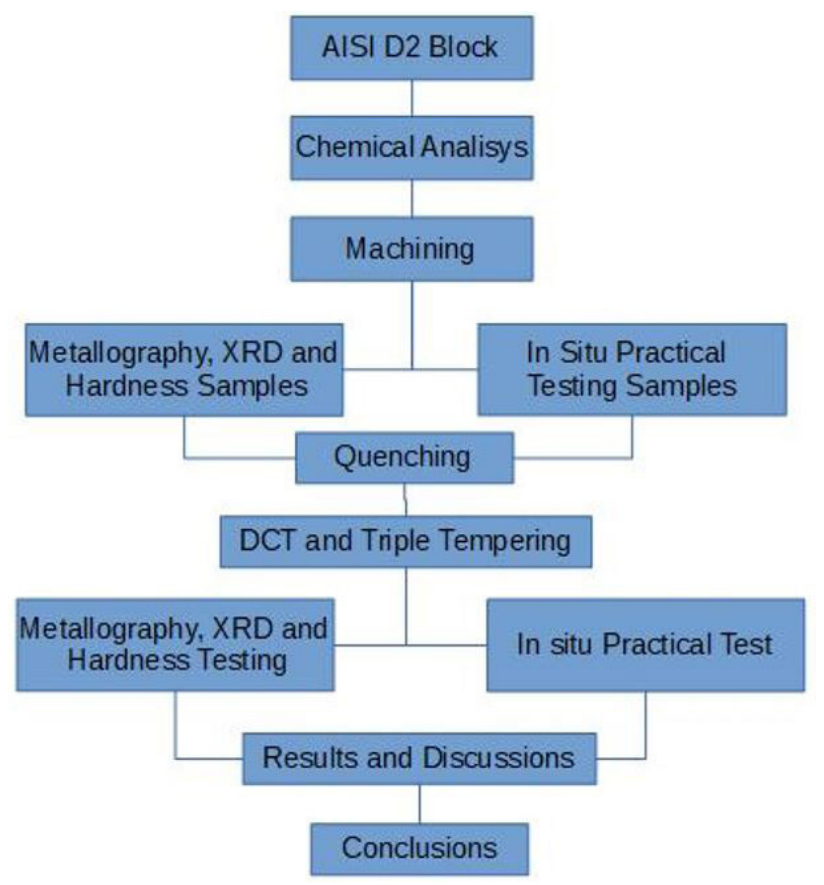

Figure 1. Block diagram showing the experimental procedure.

Samples were produced from two blocks of AISI D2 steel with dimensions $45 \mathrm{~mm}$ thick, $300 \mathrm{~mm}$ wide and $300 \mathrm{~mm}$ long. Cutting punches were made for stamping of plates. The material is a cold work tool steel AISI D2, with the chemical composition according to Table 1. Chemical analysis was tested by optical emission spectrometer from Spectro, model Spectrolab (average of 3 measurements).

Table 1. Chemical analysis of the sample

\begin{tabular}{cccccccc}
\hline \multicolumn{7}{c}{ Chemical Composition of AISI D2 [wt \%] } \\
\hline$[\mathbf{C}]$ & {$[\mathbf{M n}]$} & {$[\mathbf{P}]$} & {$[\mathbf{S}]$} & {$[\mathbf{S i}]$} & {$[\mathbf{C r}]$} & {$[\mathbf{M o}]$} & {$[\mathbf{V}]$} \\
\hline 1.51 & 0.35 & 0.018 & 0.009 & 0.43 & 12.00 & 0.92 & 0.96 \\
\hline
\end{tabular}

The tool was produced by milling, flat grinding and wire EDM (electric discharge machining) processes. Besides that, samples were produced to metallography, hardness testing and $\mathrm{X}$-ray diffraction.

\subsection{Heat treatment}

For the heat treatment of the samples and the tool a vacuum furnace was employed. The austenitizing temperature and time was $1030^{\circ} \mathrm{C}, 1 \mathrm{~h} / \mathrm{inch}$. After quenching, samples were submitted to two types of treatment: Conventional Heat Treatment (CHT) and Deep Cryogenic Treatment (DCT).

CHT consists in triple tempering after quenching in an electric convection furnace, at $530^{\circ} \mathrm{C}$ for $2 \mathrm{~h}$ each.

DCT consists in immersion in liquid nitrogen for $12 \mathrm{~h}$, following by single tempering in an electric convection furnace, at $530^{\circ} \mathrm{C}$ for $2 \mathrm{~h}$.

\subsection{Metallographic examination, Drx and hardness testing}

For metallographic examination samples were cut by abrasive cutting machine and mounted in Bakelite to better preparation. Metallography followed standard procedure [18] of grinding, polishing, and etching, followed by Optical Microscopy. Besides, to estimate the percentage of carbides the software Image J ${ }^{\circledR}$ was used. Images at $500 \mathrm{X}$ magnification were used to measuring carbides fraction area. Hardness measurements were made in a Rockwell C hardness tester (average of 3 tests). XRD measurements were performed on a flat, polished surface to evaluate the phases in the treated samples.

\subsection{Practical test}

To assess the behaviour of DCT and compare to CHT in the industry, two tools were produced and put into work with the respective treatments. The parameter used to compare the performance of the tools was the tool life between two sharpening. The results and discussion are presented in the next topic.

\section{Results and discussion}

\subsection{Metallography and X-ray diffraction}

Metallographic examination shows the presence of tempered martensite [matrix], primary carbides (PC) and secondary carbides (SC). According to Das et al. [2] and Hadi Ghasemi-Nanesa [19] Primary carbides consists in $\mathrm{M}_{7} \mathrm{C}_{3}$ stoichiometry. The secondary carbides could be $\mathrm{M}_{2} \mathrm{C}$ and $\mathrm{M}_{23} \mathrm{C}_{6}$. Large primary carbides are formed during solidification of the steel, while secondary carbides precipitates from solid solution, this why they are smaller and, therefore, implies in higher mechanical properties enhancement. Also, secondary carbides can be divided into two groups, large secondary carbides (LSC) and small secondary carbides (SSC), as shown in Figure 2.

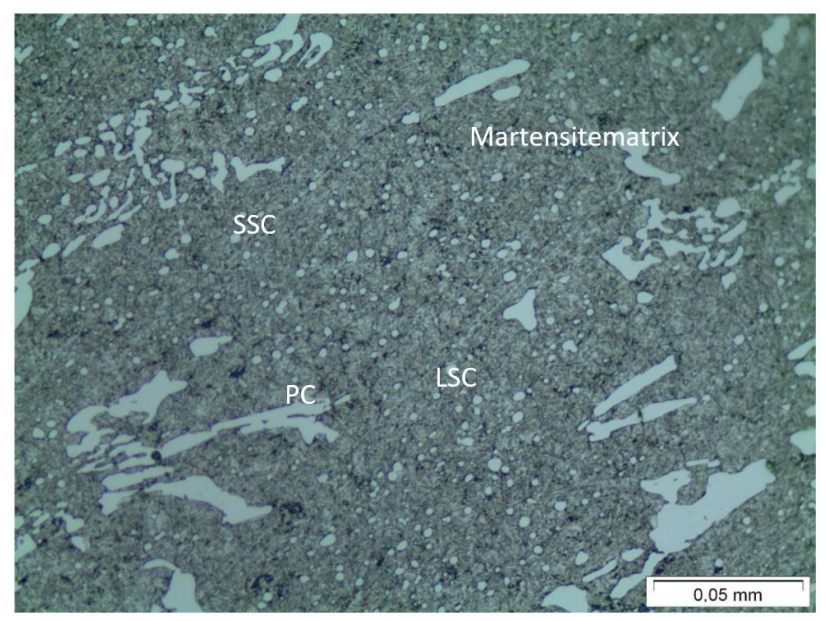

Figure 2. Micrography of CHT sample, where the martensite matrix, PC, SSC and LSC can be observed. 
Figure 3 shows the microstructure observed for the $\mathrm{CHT}$ and DCT heat treatments. It is possible to observe that secondary carbides quantity is higher for DCT in comparison to the CHT samples

According to literature $[5,20]$ the higher quantity of SSC and LSC comes from the precipitation during tempering and cryogenic stages. The carbon trapped in the martensite is released and reacts with the chromium alloying element. This kind of precipitation has coherence with the matrix lattice, therefore, higher influence on mechanical properties.

To estimate the carbides fraction image analyses techniques were applied to 500X magnification micrographs. Figure 4 shows the comparison between CHT and DCT samples.

In his study, Vitry et al. [21] suggested that the carbides in AISI D2 steel may have three types, as shown in Figure 5.

In general, in the micrographs of AISI D2 steel, a tempered martensite matrix with carbides of types MC and $\mathrm{M}_{23} \mathrm{C}_{6}$ dispersed in the matrix is observed. It appears that carbides of the type $\mathrm{MC}$ are located in the centre or at the prior austenite grain boundaries, as show in Figure 5. The presence of $\mathrm{M}_{7} \mathrm{C}_{3}$ carbides was also observed, this kind of primary carbide can present different morphology due to the hot rolling process. According to Vitry et al. [21], this type of carbide appears preferentially in regions subjected to intense cooling.

Image J was used to estimate carbides fraction, the results are shown in Table 2.

To estimate of the percentage area of carbides, only secondary carbides were counted. It is possible to observe that DCT implies in an increase about $64.8 \%$ of carbides percentage. According to Das et al. [2-4] and Moscoso et al. [22] the carbon atoms trapped into martensite lattice are expelled during DCT for the surrounding dislocations. This carbon combined with the alloying elements forms transition carbides that, over time, become finely precipitated secondary carbides of the $\mathrm{M}_{23} \mathrm{C}_{6}$ type. Also, the conditioning of the retained austenite implies in more carbon to precipitate finer secondary carbides, since in this temperature the diffusion and energy to increase the size of carbides is not enough.

Table 2. Calculation of carbides percentual area. Samples CHT and DCT

\begin{tabular}{cc}
\hline Sample & \% SECONDARY CARBIDES AREA \\
\hline CHT & 6.6 \\
DCT & 10.1 \\
\hline
\end{tabular}
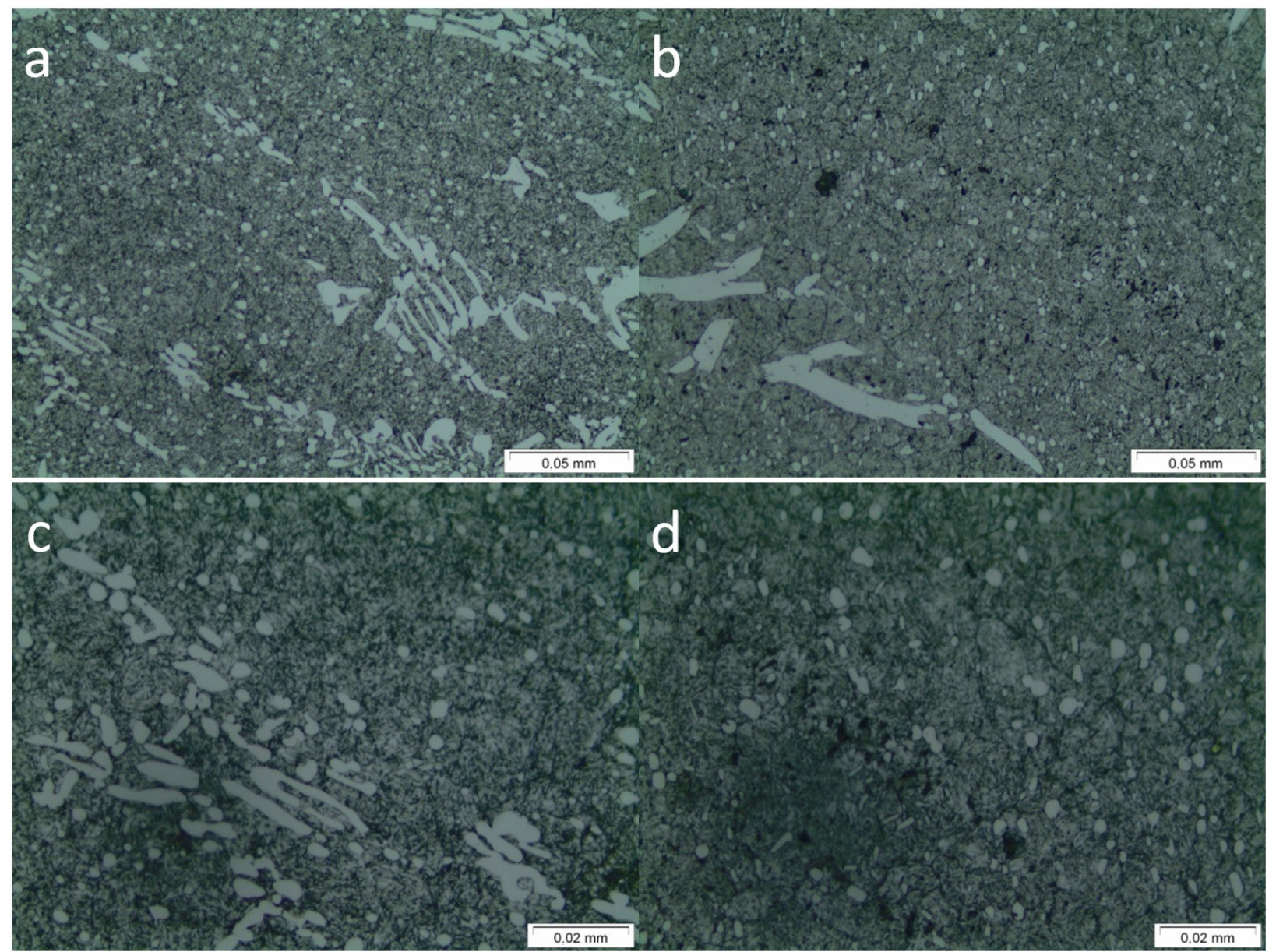

Figure 3. Lower magnification photomicrography of (a) CHT samples and (b) DCT sample. Higher magnification photomicrography of (c) CHT samples and (d) DCT sample. 

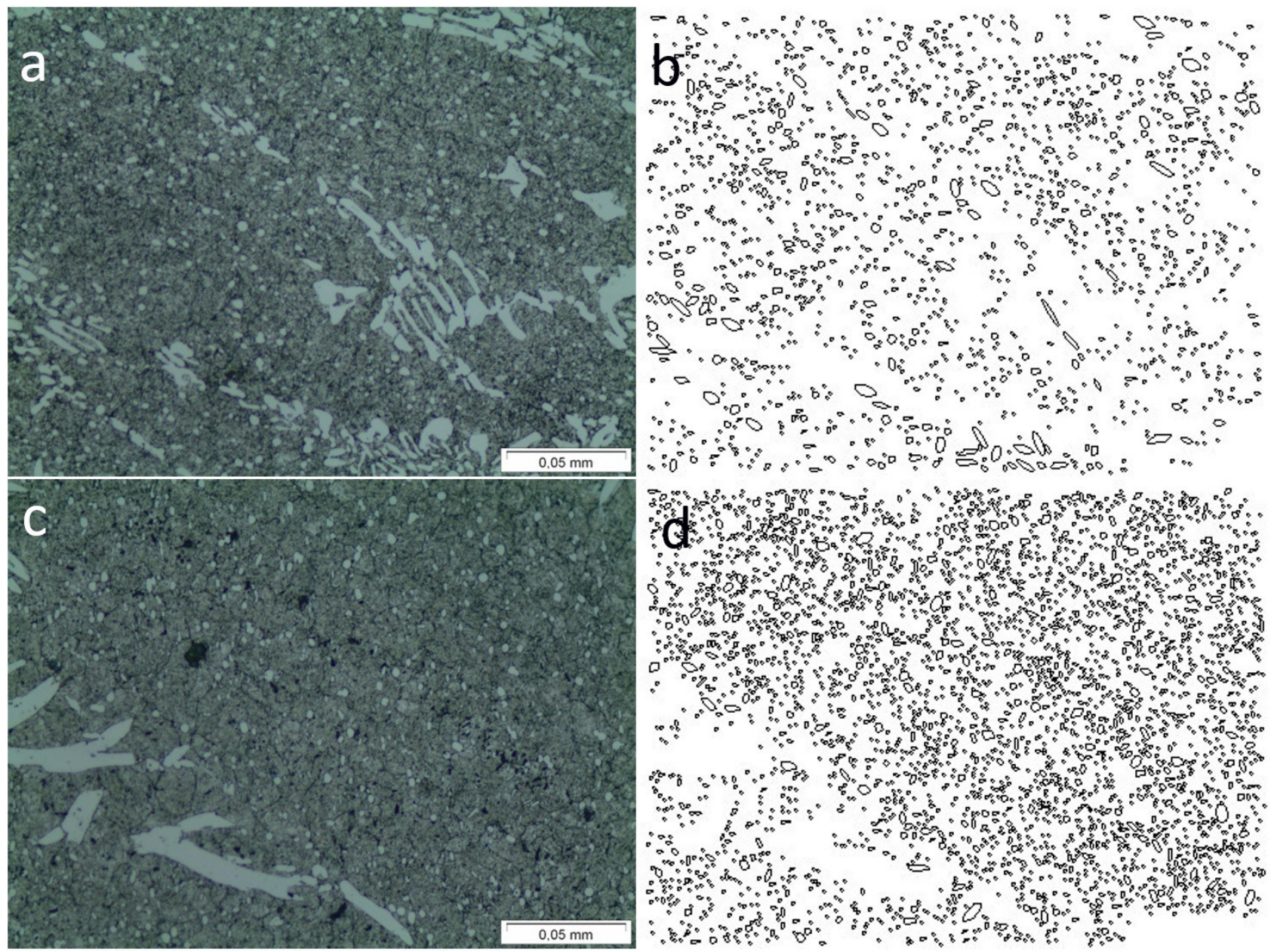

Figure 4. Binarization using ImageJ Software. (a) and (b) Sample CHT. (c) and (d) Sample DCT.

Carbide type

Morphology

Globular, isolated or associated

MC

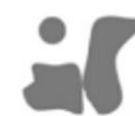

$\mathbf{M}, \mathbf{C}_{3}$

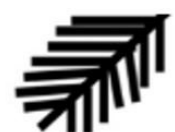

Thick lamelar like fish spine

Small isolated globular shape

\section{Preferential Location}

Grain center or boundary, also associated to M7C3

Intense cooling regions

Homogeneusly distributed in matrix

Figure 5. Carbides morphology and preferential regions in tool steels. Adapted from Vitry et al. [21]

$\mathrm{M}_{23} \mathrm{C}_{6}$ carbides of small and globular morphology show a better distribution in samples submitted to cryogenic and subsequent tempering. This observation is in line with what Amini et al. $[23,24]$ states in their article. According to the authors, cryogenic cooling facilitates the precipitation of carbides in greater proportion and better dispersed in the matrix. This is due to the contraction of the crystalline structure of metal during cryogenic treatment, promoting the diffusion of carbon atoms to dislocations or discontinuities. Figure 6 shows the results of XRD for both samples.
The intensity of $\mathrm{Cr}_{23} \mathrm{C}_{6}$ peaks obtained was not so high, this is probably due to the use of solid samples. Also some peaks were dislocated, probably due to residual stresses from the heat treatment. Still, it is possible to observe higher peaks of $\mathrm{Cr}_{23} \mathrm{C}_{6}$ in DCT samples, comparing to CHT samples. This is an indication that these carbides quantity are higher in DCT samples. Also, austenite and $\mathrm{Cr}_{7} \mathrm{C}_{3}$ peaks looks very similar, indicating that the amount of each phase is similar comparing both heat treatments. 


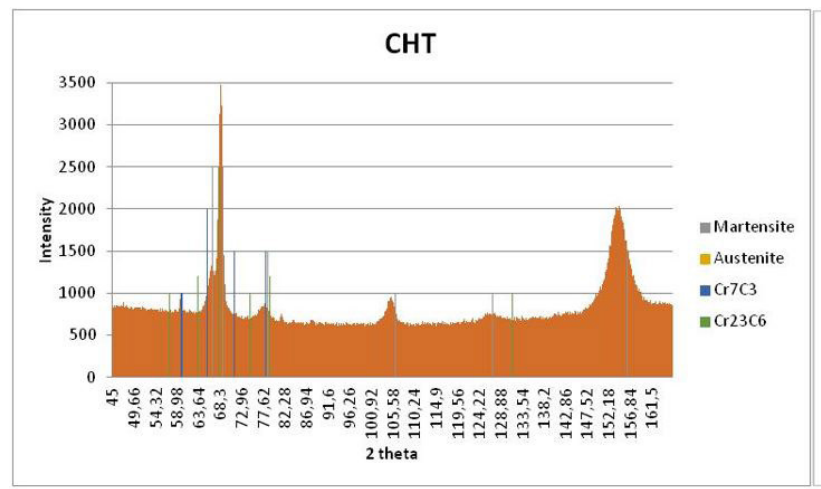

Figure 6. X-ray diffraction for CHT and DCT samples.

\subsection{Hardness measurements}

Hardness measurements shows a significant increasement in hardness after DCT, the reason is probably by transforming retained austenite into martensite [25], that was not possible to observe by light microscopy. Further tempering, reduced hardness to values close to CHT. It is important to observe that the presence of retained austenite not only decreases the hardness but, also implies in the possibility of transformation in martensite during work. This non tempered martensite promotes distortion and also reduces tool life due to brittleness, as shown in Figure 7.

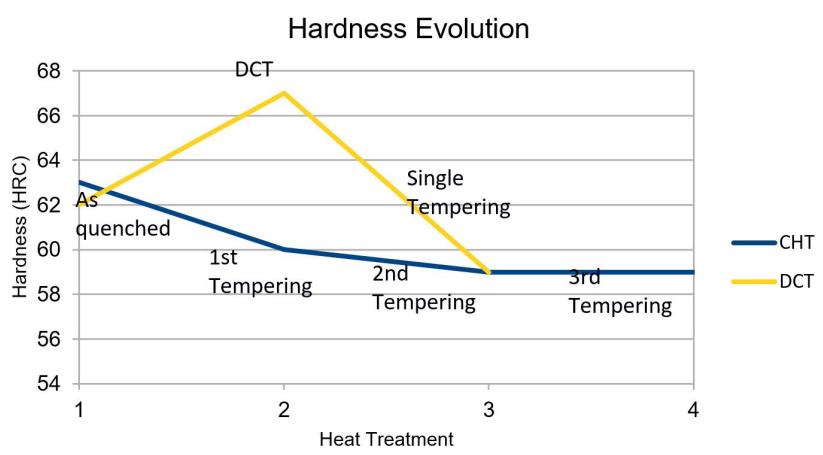

Figure 7. Hardness evolution after CHT and DCT.

\subsection{In Situ practical testing}

To develop the practical test, cutting punches were treated by CHT and DCT and placed to stamp platelets at a large automotive company. The stopping criterion used was the formation of burrs on the produced part. Treated cutting punches were used at random days. The industrial application showed that the DCT samples showed superior tool life in all tests. The average number of pieces made for the DCT samples was 8050.5, while for the CHT samples it was 5353.7. That means an increasement of 50.3\% in tool life. The formation of a high resistance martensitic matrix with the formation of fine, well distributed, carbides results in higher toughness [26]. The results of industrial application are shown in Figure 8.
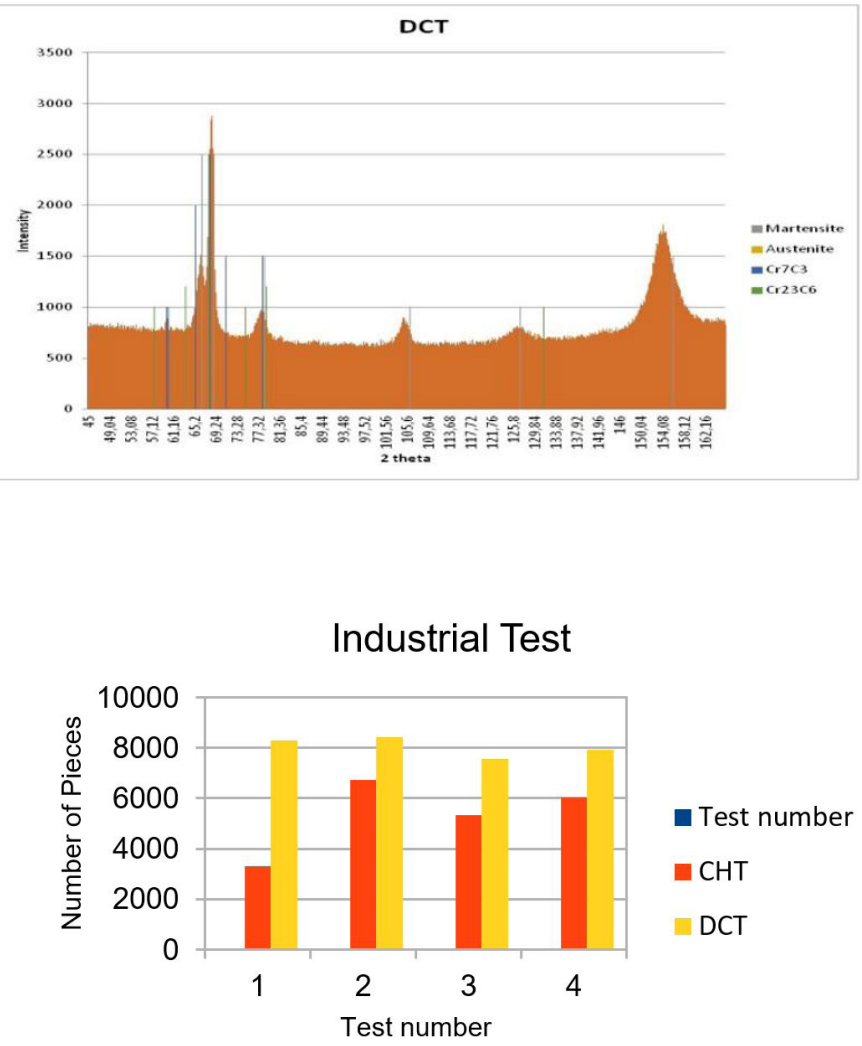

Figure 8. Industrial application of cutting punches.

\section{Conclusions}

From the results obtained by this work it is possible to conclude that:

1. It was possible to improve tool life by applying deep cryogenic treatment to cutting punches of AISI D2 tool steel;

2. The use of DCT produced higher carbide precipitation when compared to CHT;

3. Tool life improvement was about $50 \%$ comparing to conventional heat treatment;

4. It was possible to improve steel properties with a single tempering after DCT. It implies in energy cost reduction.

\section{Acknowledgements}

The author likes to thanks IFRS, LAMEF/UFRGS, Fras-le S.A. and TERMO AÇO TRATAMENTOS TÉRMICOS. The authors would like to dedicate this work to the memory of Professor Telmo Strohaecker.

\section{References}

1 Das D, Ray KK, Dutta AK. Influence of temperature of sub-zero treatments on the wear behaviour of die steel. Wear. 2009;267(9-10):1361-1370. 
2 Das D, Sarkar R, Dutta AK, Ray KK. Influence of sub-zero treatments on fracture toughness of AISI D2 steel. Materials Science and Engineering A. 2010;528(2):589-603.

3 Das D, Dutta AK, Ray KK. Sub-zero treatments of AISI D2 steel: Part I. Microstructure and hardness. Materials Science and Engineering A. 2010;527(9):2182-2193.

4 Das D, Dutta AK, Ray KK. Sub-zero treatments of AISI D2 steel: Part II. Wear behavior. Materials Science and Engineering A. 2010;527(9):2194-2206.

5 Moscoso MFC. O efeito da taxa de resfriamento e tratamento criogênico sobre a tenacidade à fratura do aço ferramenta ABNT D2. [Dissertação de mestrado]. Caxias do Sul: IFRS; 2017.

6 Korade N, Ramana KV, Jagtap KR, Dhokeyc NB. Effect of deep cryogenic treatment on tribological behaviour of D2 tool steel - an experimental investigation. Materials Today, Proceedings. 2017;4(8):7665-7673.

7 Sonar T, Lomte S, Gogte C, Balasubramanian V. Minimization of distortion in heat treated AISI D2 tool steel: mechanism and distortion analysis. Procedia Manufacturing. 2018;20:113-118.

8 Donachie SJ, Ansell GS. The effect of quench rate on the properties and morphology of ferrous martensite. Metallurgical Transactions. A, Physical Metallurgy and Materials Science. 1975;6:1863-1875.

9 Kokosza A, Pacyna J. Evaluation of retained austenite stability in heat treated cold work tool steel. Journal of Materials Processing Technology. 2005;162-163, 327-331.

10 Nanesa HG, Jahazi M, Naraghi R. Martensitic transformation in AISI D2 tool steel during continuous cooling to 173 K. Journal of Materials Science. 2015;50(17):5758-5768.

11 Badeshia H, Honeybombe R. Steels, microstructure and properties. 4th ed. London: Elsevier; 2017.

12 Su YY, Chiu L-H, Chuang TL, Huang C-L, Wu CY, Liao KC. Retained austenite amount determination comparison in JIS SKD11 steel using quantitative metallography and X-ray diffraction methods. Advanced Materials Research. 2012;482-484:1165-1168.

13 Gill SS, Singh J, Singh R, Singh H. Metallurgical principles of cryogenically treated tool steels-a review on the current state of science. International Journal of Advanced Manufacturing Technology. 2011;54(1-4):59-82.

14 Torkamani H. Raygan; Rassizadehghani, J. Comparing microstructure and mechanical properties of AISI D2 steel after bright hardening and oil quenching. Materials \& Design. 2014;54:1049-1055.

15 Ghasemi-Nanesa H, Jahazi M. Simultaneous enhancement of strength and ductility in cryogenically treated AISI D2 tool steel. Materials Science and Engineering A. 2014;598:413-419.

16 Oppenkowski A, Weber S, Theisen W. Evaluation of factors influencing deep cryogenic treatment that affect the properties of tool steels. Journal of Materials Processing Technology. 2010;210(14):1949-1955.

17 Ghasemi Nanesa H, Jahazi M. Alternative phase transformation path in cryogenically treated AISI D2 tool steel. Materials Science and Engineering A. 2015;634:32-36.

18 ASTM International. ASTM E3: standard guide for preparation of metallographic specimens. West Conshohocken: ASTM International; 2011. p. 1-12.

19 Ghasemi-Nanesa H, Jahazi M. Simultaneous enhancement of strength and ductility in cryogenically treated AISI D2 tool steel. Materials Science \& Engineering A. 2014;598:413-419.

20 Vahdat SE, Nategh S, Mirdamadi S. Effect of microstructure parameters on tensile toughness of tool steel after deep cryogenic treatment. International Journal of Precision Engineering and Manufacturing. 2014;15(3):497-502.

21 Vitry V, Nardone S, Breyer J-P, Sinnaeve M, Delaunois F. Microstructure of two centrifugal cast high speed steels for hot strip mills applications. Materials \& Design. 2011;34:372-378.

22 Moscoso M, Ramos FD, Cunha PHCP, Lessa CL, Toniolo J, Lemos GVB. Effects of cooling parameter and cryogenic treatment on microstructure and fracture toughness of AISI D2 tool steel. Journal of Materials Engineering and Performance. 2020;1:1.

23 Amini K, Nategh S, Shafyei A. Influence of diferentecryotreatments on tribological behavior of $80 \mathrm{CrMo12} 5$ cold work tool steel. Materials \& Design. 2010;31:4666-4675.

24 Amini K, Akhbarizadeh A, Javadpour S. Effect of deep cryogenic treatment on the formation of nano-sized carbides and the wear behavior of D2 tool steel. International Journal of Minerals Metallurgy and Materials. 2012;19(9):795.

25 Li S, Xiaoa M, Yea G, Zhaoa K, Yang M. Effects of deep cryogenic treatment on microstructural evolution and alloy phases precipitation of a new low carbon martensitic stainless bearing steel during aging. Materials Science and Engineering A. 2018;732:167-177. 
Deep cryogenic treatment in AISI D2 tool steel punches to enhance tool life

26 Podgornik B, Paulin I, Zajec B, Jacobson S, Leskovšek V. Deep cryogenic treatment of tool steels. Journal of Materials Processing Technology. 2016;229:398-406.

Received: 14 Aug. 2020

Accepted: 16 Dec. 2020 